\title{
Sociology and the Problem of Order
}

In April 2017 the editorial board of Russian Sociological Review announced a call for papers for its regular annual special issue. We invited scholars from a broad range of social science disciplines to reflect on one of the core problems of sociology - social order. The papers collected here are valuable contributions to their respective fields covering this more general one. We selected them from many proposals and draft manuscripts under a meticulous procedure of peer-review but, while being satisfied with the result of this selection, we cannot but confess a slight disappointment reconsidering our own starting point. It seems less sophisticated now; we could have got more diverse papers if we formulated better what we aimed to achieve. While still recognizing the role of globalization and the omnipresence of global flows, financial institutions, and cultural patterns of everyday action worldwide, we aimed to produce a volume composed of papers dedicated to various instances of what seems to be disorderly practices but eventually turns out to be a specific form of order. Spontaneous orders, we argued in our call for papers, "may reveal themselves in various configurations of order and disorder, in unprecedented or partially transformed situations, or in episodes of social life in time and space. The novelty may be traced by unexpected events or by issues of communication, by the distribution of sources and by the shifting of centers of activities, or by the composition of new types of inert communication. Spontaneous orders relate to the shop floor of the Social where new forms of interaction emerge and get tested. The times and situations, when the dominant tendencies are not yet defined, and the future is still open, are the most favorable to these orders." Now it is time to revisit our initial concerns to add a few lines of further clarification for our starting position.

This issue is a part of a larger project of the Centre for Fundamental Sociology. In recent years we have been trying to re-arrange the basic concepts of social science and make them more appropriate for catching new changes in social reality. For us, they are not ahistorical, sterilized tools of analysis but - in a sense - something that belongs to the social reality itself. We cannot think of any theoretical work without the relevant historical studies of the concepts. In our studies of the history of social and political thought we go centuries back to follow the complicated dynamics of seemingly universal concepts, such as state, society, power, authority, conflict. The same can be said about more recent concepts. Every historian of political thought knows that concepts are slow

\footnotetext{
(C) Alexander F. Filippov, 2017

(C) Nail Farkhatdinov, 2017

(C) Centre for Fundamental Sociology, 2017

DOI: $10.17323 / 1728-192 \mathrm{X}-2017-4-7-13$

* The publication of this paper is supported by the Basic Research Program of the National Research University Higher School of Economics.
} 
to change, they are not simply reflections of social reality but rather outdated descriptive tools. That is the penalty: researchers regularly apply concepts which bear traces of previous decades (if not centuries) to situations which are changing dramatically. It was our idea to take a step forward before the inadequacy of the commonly accepted conceptions strike back.

In the announcement we wrote:

Undoubtedly, we agree that today's global phenomena such as flows and networks cover the world and horizontal connections continue to be omnipresent like any other new global social institution. Yet nowadays, radical changes are taking place that will become more sophisticated on the global scale, and will question and reduce the importance of what used to be a symptom of globalization. This is exemplified through the new reinforcement of the State, the reducing power of international legal institutions and the authority of the international organizations, the emergence of new forms of spontaneous order everywhere, and the growing avalanche of information on various episodes of social interaction. Globalization is questioned with respect to the process of the blurring of political borders of states and other territories. Where social events take place, states gain their role as a main social unity anew. Still, they are permeated by global flows. The interaction of the global and the local takes a new shape. Furthermore, new forms of social interaction emerge, and it is not possible to definitely classify them as global or local. Neither traditional institutional nor newer network- and flow-inspired languages of description can be used to make sense of them. These interactions - often spontaneous, slightly formed, and embedded in the routine practices - may emerge and then quickly dissolve. However, they may become the origin of the yet-unknown future.

So, we tried to discard outdated views and conceptions, however, the idea of globalization being still in fashion, preoccupied our arguments even in the form of critical evaluation. It overshadowed two more significant concepts, central for any practically oriented sociological theory: event and order.

The concept of event appears here as a terminus technicus taken for granted by everybody; although a category of great importance, it is rarely clarified in sociological texts. For us, social events occurring in space and time are something that can be directly observed in social life. Nobody has ever seen a system, an institute or even a (the) society or social action. What we (both as lay agents and sociologically trained observers) can get immediate access to are always events as occurrences correlative to observations. They would be remembered, narrated or expected. Through expectations and narrations, we get the order of events. Every social order would be considered then as an order of events, absent in the past, emerging now and passing away in the future. If we are interested in what is occurring, we need an optic to observe events so that we can narrate a story remembering the sequences or circulations of events or describe future events as being expected according to the experience of their occurrences. Therefore, for a thick description of social reality we need not any theory but several narrations about events or, better, descriptions of ordered events in narrated episodes. 
We also need a more elaborated conception of spontaneous order. For the classics of social sciences, order was one of the central concepts. "Order and progress", "the Hobbesian problem of order", "How is social order possible?", "There is no Order in the Plenum" - these are the most famous formulations. According to Robert A. Nisbet, "[t]he fundamental ideas of European sociology are best understood as responses to the problem of order created at the beginning of the nineteenth century by the collapse of the old regime under the blows of industrialism and revolutionary democracy"1. Those responses contained, in turn, other, more modern ideas of order. The concept of order was to be found at the core of the theories now generally acknowledged as classical. Sociology as a great project claimed the place traditionally occupied by the philosophy of law and politics. The social was its mode of thinking about order. Social order would be established amidst the social by the social itself. Niklas Luhmann, the last sociologist of the last century to be aware of the consequences of the radical break with the traditions sociology undertook, described it once as follows: "Classical social theories have answered the question of what makes social order possible by reference to normative conditions: to natural law, the social contract, or consensual morality. This has also been true for sociology, for Durkheim, and for Talcott Parsons. However, Parsons pointed the way to an alternative, which is not, however, unchecked but assigned to the still normative meaning of codes and shared symbolic values. It lies in the theory of symbolically generalized media"2. Sociology inherited from earlier legal and political thought not only the idea of order as such but also the idea of a normative order, produced in a society which solves its problems after the revolutionary downfall of the traditional hierarchy of orders. However, in Parsons' theory of action and system integration Luhmann saw another way of thinking about order, without direct appeal to consensual agreement and generally accepted norms. Luhmann elaborated and radically transformed this theory to free it from superfluous normative content. For him, interconnected communications became momentarily operations of self-creating (autopoietic) systems. In fact, he no longer needed the concept of order. We shall come back to this.

The idea of order appears more often not in sociology but in other social sciences; it looks today - at least in respect to Google search — as mainly the libertarian and even anarchistic concept. Thousands of publications referring to F. A. von Hayek, L. von Mises, M. Rothbard etc. as the founding fathers of spontaneous order theories belong to this discursive field and demonstrate a rather slow development in its main arguments ${ }^{3}$. As Stephan Kinsella puts it, "modern libertarian theory is only about five decades old", and after five decades of development "there remains a need for treatments of the ideas of liberty that are explicitly anchored in antistate, Austrian-Misesian, and systematic Rothbardian ideas"4. Just a couple of arguments taken from the works of von Hayek will il-

1. Nisbet R. A. (2009). The Sociological Tradition. New Brunswick: Transaction. P. 21.

2. Luhmann N. (2012). Theory of Society, Vol. 1. Stanford: Stanford University Press. P. 190.

3. See e.g. an earlier attempt at reconstructing this tradition of thought in: Barry N. (1982). The Tradition of Spontaneous Order // Literature of Liberty. Vol. 5. № 2. P. 7-58.

4. Kinsella S. N. (2015). Foreword // Rachels C. A Spontaneous Order: The Capitalist Case for a Stateless Society. CreateSpace. P. 7, 9. 
lustrate this idea ${ }^{5}$. In Law, Legislation and Liberty he describes the distinction drawn between made order and spontaneous order as follows: "The made order which we have already referred to as an exogenous order or an arrangement may again be described as a construction, an artificial order or, especially where we have to deal with a directed social order, as an organization. The grown order, on the other hand, which we have referred to as a self-generating or endogenous order, is in English most conveniently described as a spontaneous order" ${ }^{\prime \prime}$. Whereas made order, or taxis, would be of moderate complexity, concrete (perceived) and arranged purposely, grown (spontaneous) order, or cosmos, can (but would not necessary) be of great complexity; "they will often consist of a system of abstract relations between elements which are also defined only by abstract properties, and for this reason will not be intuitively perceivable and not recognizable except on the basis of a theory accounting for their character" ${ }^{\prime \prime}$. An individual action can be purposive but an order of actions or an order as an aggregated result of actions will be not. Hayek did not belong to sociology in the narrow sense. More striking are the resemblances between his explications of order and those of, say, Talcott Parsons ${ }^{8}$. Here is another quotation from Hayek: "The order of society is therefore a factual state of affairs which must be distinguished from the regularity of the conduct of individuals. It must be defined as a condition in which individuals are able, on the basis of their own respective peculiar knowledge, to form expectations concerning the conduct of others, which are proved correct by making possible a successful mutual adjustment of the actions of these individuals". These theoretical elaborations could be of first-rank importance to sociology but were largely ignored by the discipline which took its own direction. The theory of spontaneous order influenced other areas of knowledge; it was not sociology but another project of a general theory of action. The same can be said about the praxeology of von Mises. The ideological, libertarian bias of the theories of this kind was one of the reasons why they remained without much influence on sociology.

The proponents of spontaneous order trace it back to through a centuries-long tradition reaching to John Locke and even to Hugo Grotius. Sociologists could say the same about the history of their science - when the history of their science was important for them. The tradition of sociology is broken now, as far as sociologists refuse the concept

5. See: Kley R. (2011). Hayek's Social and Political Thought, New York: Oxford University Press. P. 26ff., 111ff. for a thorough reconstruction of von Hayek's conception of spontaneous order.

6. Hayek F. A. (1983). Law, Legislation and Liberty, Chicago: University of Chicago Press. P. 37.

7. Ibid. P. 39 .

8. Cf.: "Factual order . . connotes essentially accessibility to understanding in terms of logical theory, especially of science. ... Normative order, on the other hand, is always relative to a given system of norms or normative elements whether ends, rules or other norms. Order in this sense means that process takes place in conformity with the paths laid down in the normative system" (Parsons T. [1966]. The Structure of Social Action. New York: The Free Press. P. 91). The following, with reference to Max Weber's distinction drawn between an order based on agreement and an imposed order, is also worth mentioning: "[F]or one who holds an order to be legitimate, living up to its rules becomes, to this extent, a matter of moral obligation" (Ibid. P. 661).

9. Hayek F. A. (1982). New Studies in Philosophy, Politics, Economics and the History of Ideas. London: Routledge. P. 9. 
of order ${ }^{10}$. Fields, systems, networks and the like supersede order in sociology. Other disciplines re-establish themselves as the sciences of social order. We are trying to demonstrate, that in sociology, nevertheless, the concept still remains fruitful; this is a source not to be neglected.

Let us confront Hayek with Luhmann again ${ }^{11}$. They both studied the organization of events. The differences are nonetheless great. For Hayek, significantly organized events were (if not the cosmic occurrences of nature) "events of actions"12. Actions are done by individuals with or without any idea of order in mind. "While the deliberate use of spontaneous ordering forces (that is, of the rules of individual conduct which lead to the formation of a spontaneous general order) thus considerably extends the range and complexity of actions which can be integrated into a single order, it also reduces the power anyone can exercise over it without destroying the order. The regularities in the conduct of the elements in a cosmos determine merely its most general and abstract features" ${ }^{13}$. Hayek, therefore, is not interested in the sustained production of different restricted orders through spontaneous activity. Rules are akin to law; law and legislation are the visible purpose of his basic statements ${ }^{14}$. For Luhmann, as we mentioned, events are communications. Communications are elements, i.e., they have their component parts but cannot be divided into those parts again, each communication is related to another communication, it has meaning through its relations to other communications, not to any events in the world. "All operations in coupled systems are only events that are over as soon as they occur. They must therefore produce the difference from the environment through a sequence of matching operations. This requires memories specific to systems. Although the memory participates only in the system's own operations, remembering or forgetting only its own operations, it presents the outcomes (products) of operations on the basis of the distinction between self-reference and other-reference" ${ }^{15}$. This is the most problematic point. What is the sequence? For Luhmann, it is a circular relation. Events are over as soon as they occur, however, through the memory of the system, the events emerging now are related to the previous events of the same sequence. "The theory of

10. "[T]he eternal problems of social order", Richard Grathoff wrote in his Introduction to the SchutzParsons correspondence (Grathoff R. [1978]. Introduction // Grathoff R. (ed.). The Theory of Social Action: The Correspondence of Alfred Schutz and Talcott Parsons. Bloomington: Indiana University Press. P. XXI), however, in sociology, it does not seem so eternal now as it used to be. Erving Goffman's "the interaction order" and Harold Garfinkel's explications of the order of ordinary practices are rather exclusive options, not the mainstream of contemporary sociology. Cf.: Kim K.-ki. (2003). Order and Agency in Modernity: Talcott Parsons, Erving Goffman, and Harold Garfinkel. Albany: State University of New York Press.

11. Cf. the excellent contribution by Guilherme Vasconcelos Vilaça (Vasconcelos Vilaça G. [2010]. From Hayek's Spontaneous Orders to Luhmann's Autopoietic Systems // Studies in Emergent Order. Vol. 3. P. 50-81). However, we cannot accept his main idea. The theory of an autopoietic system is not another and better version of the concept of order. It rather precluded Luhmann from making his theory more flexible.

12. The notion itself comes from Parsons.

13. Hayek. New Studies. P. 75.

14. In Vasconcelos Vilaça's concise wording, "law is the stepping stone of the entire analysis of social order by Hayek. In fact, he admits that the spontaneous order of market (and action in general) crucially depends on the existence of specific legal arrangements" (Vasconcelos Vilaça. Op. cit. P. 54).

15. Luhmann. Op. cit.. P. 66. 
complexity then requires recursive operations, in other words recursion to and anticipation of other, non-actual operations in the same system. It then no longer suffices to represent system development as a decision tree or cascade; recursion itself becomes a form in which the system enables boundaries to be drawn and structures to be formed"16. There is however no reason to identify these non-actual operations as always the operations in the same system. If Hayek too readily presupposes law as a condition for spontaneous orders, Luhmann too readily presupposes systems as the most appropriate place for communicative events. He was the only one who correctly elaborated the key notion of the event of communication, however, he could have - but he did not - take a step in another direction, towards a theory of multifold orders of communication, instead of to a theory of autopoiesis and autopoietic systems. Memory, recursion and "sameness" do not mean systems only. He could learn something more from Hayek, Goffman and Garfinkel. This is what remains to be done. Through a unified theory of communication, through a re-thematization of the history of political philosophy, the unity of social sciences can be re-established with a new interest in the concept of order. We can find and make more use of these resources if we take them without theoretical prejudice or dogma.

At the end of this brief reconsideration of our call for papers, we would like to introduce the papers that compose the special issue this year.

A historical account of the origins of the notion of spontaneous order opens the issue. The paper by Alex Law provides a theoretical ground for the understanding of spontaneous order and compares the writings of the Scottish Enlightenment and the sociology of Norbert Elias. The paper argues that the contemporary globalized world often labeled as neoliberal and globalized can be more adequately described once the vocabulary of relational sociology - a dominant one nowadays - is revised. Alex Law suggests that going back to the Scottish Enlightenment and Norbert Elias' figurational sociology provides conceptual insights for the empirical work related to the understanding of the contemporary controversies of the interrelations of state, society and market. The next paper by Georg P. Mueller addresses the processes of how social order emerges in a more classical and methodologically rigorous way. Using mathematical modeling the paper approaches political processes and particularly protests, and studies the strategies of how a new social order may emerge as a result of protests, i.e. via the government's response towards protests. Karine Clément presents the results of empirical studies of how people from lower classes in Russia cope with instability and atomization and still engage in the processes of building social ties and networks. In doing this she introduces one of the mainstream sociological agendas to our issue - precarity. Despite the fact that spontaneity and the emergent nature of contemporary spontaneous order is often difficult to grasp within conventional notions, precarity provides an example of an influential domain of research that puts this task in the forefront. The second paper dedicated to precarity discusses the nature of labor in contemporary society. It does not seem surprising at all that this field of research has become the most sensitive to the issue of spontaneous order. In their paper

16. Ibid. P. 8o. Italics added. 
Vyacheslav Bobkov and Vadim Kvachev focus on the significant transformations that the contemporary labor market undergo and argue - quite conventionally - that old sociological notions are not relevant anymore. In general precarity has become more than just an academic notion and this fact shows that despite the mainstream preoccupation with transformations there is still demand for the discussion of what social order looks like at least in the field of labor. The final paper of the issue by Maxim Ni and Pavel Lisitsyn explores another widespread topic of contemporary studies of globalization and identity cosmopolitanism. Their paper uses a micro-sociological approach (ethnomethodology and interaction rituals theory) in order to reveal how cosmopolitan sociability takes form and stabilizes on the basis of spontaneous forms of interaction and communication. It is an example of how micro-sociological studies can be integrated into the studies of order which are often considered to be macro-phenomena in the mainstream sociological tradition.

The issue also contains three book reviews. Alexander Marey's review considers the book by José-Luis Villacañas in political theology and philosophy and in this respect may be of interest to those who are more concerned with the genealogy of concepts and the studies of political order. The reviews by Irina Trotsuk and Anna Yampolskaya are dedicated to the books that approach what are commonly considered to be non-sociological issues - love and depression. According to Trotsuk, the book by Eva Illouz Why Love Hurts: A Sociological Explanation enables us to see in love more than just a romantic feeling but a foundational opportunity for contemporary people to build up their identities and self-respect. Experiences of Depression by Matthew Ratcliffe reviewed by Anna Yampolskaya looks at depression from a phenomenological perspective, yet the reviewer recommends the book to sociologists since it challenges many of the notions that social scientist takes for granted (such as "situatedness" and agency).

With this issue we hope to continue the discussion of key fundamental issues of contemporary sociology and to draft a possible direction of future research.

Alexander F. Filippov

Nail Farkhatdinov 